\title{
A study on perceived value as a parallel between quality and kitsch in the design assessment of industrial products
}

\author{
Alexandra Elena Crăciun \\ University Politehnica of Bucharest, Department of Manufacturing Engineering, \\ Bucharest, Romania \\ craciun_alexandra@outlook.com
}

\begin{abstract}
The present paper represents a study that examines the relationship between the concepts associated with kitsch and quality approached as antagonistic concepts, for which was considered the direct connection to the product and its defining characteristics described as the product features, colour, form, material and dimensioning. Considering the relative influence of the proposed features, it was generated a series of concepts that represent the basis of the analysis format, on which numerical values will be assigned. The research contributes to industrial product design assessment in the situation where the product is approached from the perspective of the intrinsic components of the perceived value, being proposed an analysis model that starts from the relative importance ratios of the product features considered in direct relation with a correspondent assigned value.
\end{abstract}

Keywords. perceived value, quality, kitsch, product design, industrial design assessment.

\section{Introduction}

Kitsch is often surrounded by ambiguity and it is not always a fully aware occurrence, however, when a product is labelled as kitsch, it is a generally valid fact that it will be related to negative aspects. Stating an exact definition can be quite intricate, however, kitsch is generally associated with bad taste $[1,2,3]$, a form of denigration [4] and desecration of acknowledged symbols [5], symbols that could be taken out of context and reproduced graphically on mass products defined by a completely different destination [3]. Although it is not a novelty concept, kitsch is a widely debated issue and a complex phenomenon [6], its absolute removal not being a valid option since the associated products are still successful and it is quite difficult to eliminate them given the constant demand. While it is surrounded by so many negative associations, kitsch continues to persevere, whereas the attraction to it is justified by various reasons, as it is seen as innocent joy and a break from daily responsibilities [2], generating the feeling of relaxation as a form of hedonism [7], even becoming a way of emotional security [8] as nostalgia and the need for belonging. Kitsch is related to products that usually lack in functionality or their function is shaded by a prominent ludic character. Even though playfulness can have positive associations and interactivity and be useful especially in the case of products defined by multiple functions and can even guide attention and facilitate usability, however, taking into account the fact that a playful product on its own that is not defined by functionality and can be more playful than actually useful, it is no surprise that kitsch tends to be considered worthless [8], all the more so as an imposed form of ludic character can become a misinterpreted representation of creativity that could directly affect the product and the perception on it. 
Most of the time kitsch is highlighted in pseudo-art [9] or artisanal products intended for tourist consumption as souvenirs and as demand had an incremental growth such products have become mass-produced, the concept being taken over in the end even in consumer goods industrially produced, which has a direct impact on mass consumption. As a social issue, even though it can be present in products intended for all social categories even in art [1], kitsch is often associated with the lower classes, as it is considered to be the need of the masses to access consecrated objects of symbolism that the economical - social context would not normally provide access to [10], its appeal to it being possibly due to cultural conditioning and limited access to education [6] or low cultural appraisal [11]. This can be also translated in the lack of consumer education [12] which is in a direct relationship with the perceived value of the product [13].

The perceived value is reflected not only by the association with kitsch, at the opposite end of the analysis, even with greater impact, the way in which customers perceive a product can also be reflected in terms of quality [14]. Moreover, there are common aspects that can be considered, such as the emotional component [15], however there is a strong difference in the way they are reflected, being relevant to what extent a prominent form of meaning represented most often by the strong reproduction of other already existing concepts can do more harm instead of providing an appropriate meaning in accordance with the product symbolism as a representation of personality, which further highlights the way in which the two components can be approached antagonistically. The basic component of the perceived value of the product is represented by its price [16], however, the purpose of the current study is to explore the intrinsic components [17] that are in direct relation to the product, its characteristics and the way they intertwine, considered as attributes.

\section{Delimitation and analysis of concepts}

Taking into account the components generally associated with quality [18] as well as the perceived quality $[14,19]$, the design assessment dimensions were considered in relation to them [20]. As a parallel to these, in the presented study were also considered the elements generally associated with kitsch as previously described and presented in Figure 1. Thus, the purpose of the analysis is to identify the aspects related to the two categories which can influence the final design of the product, being highlighted the fact that they do not intertwine directly but even more so they are defined by concepts that are in opposition to one another.

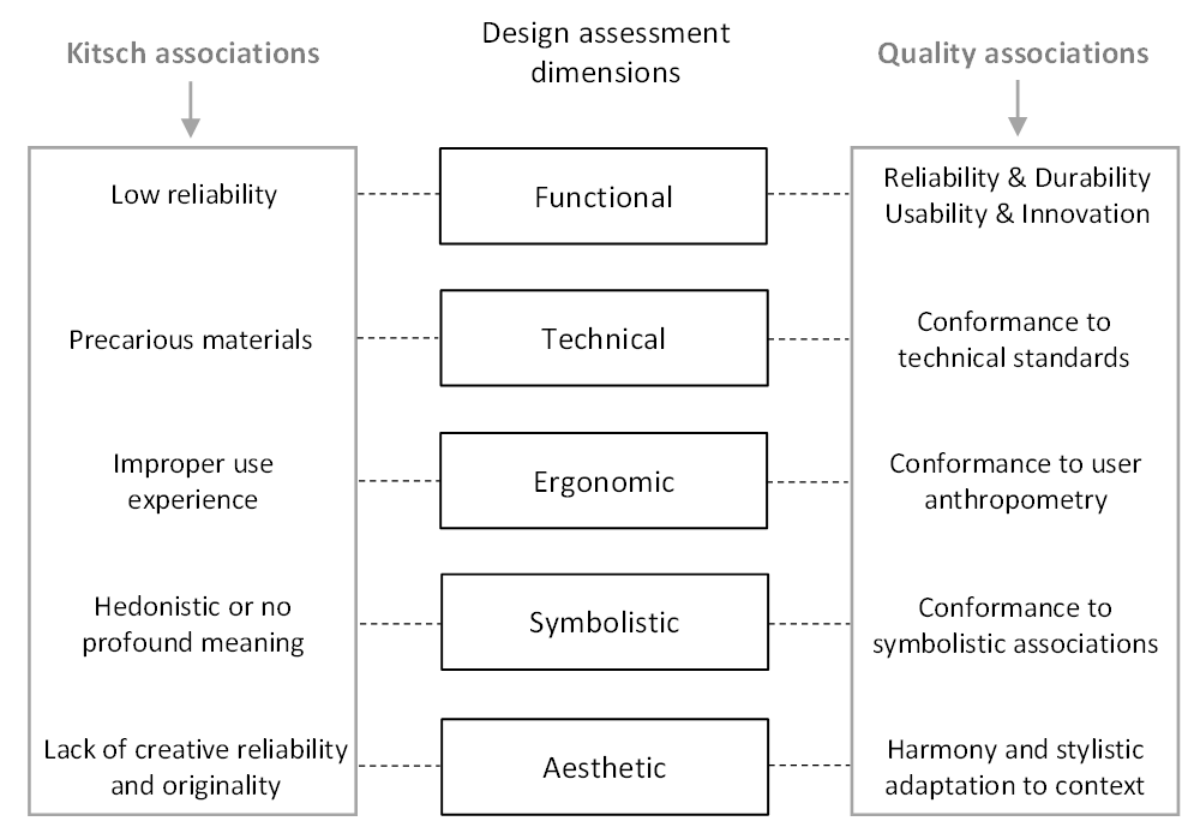

Figure 1. Associations of kitsch and quality from the perspective of design assessment dimensions 
The concepts based on the design dimensions previously presented were transposed in Figure 2 as attributes in direct relation to the elements that define the product, being considered for the proposed study the following product features: colour described as the product's colour scheme and its implications, the form of the product that includes the general form and decorations, the material as the ensemble of component materials and the dimensioning as sizing elements of the product.

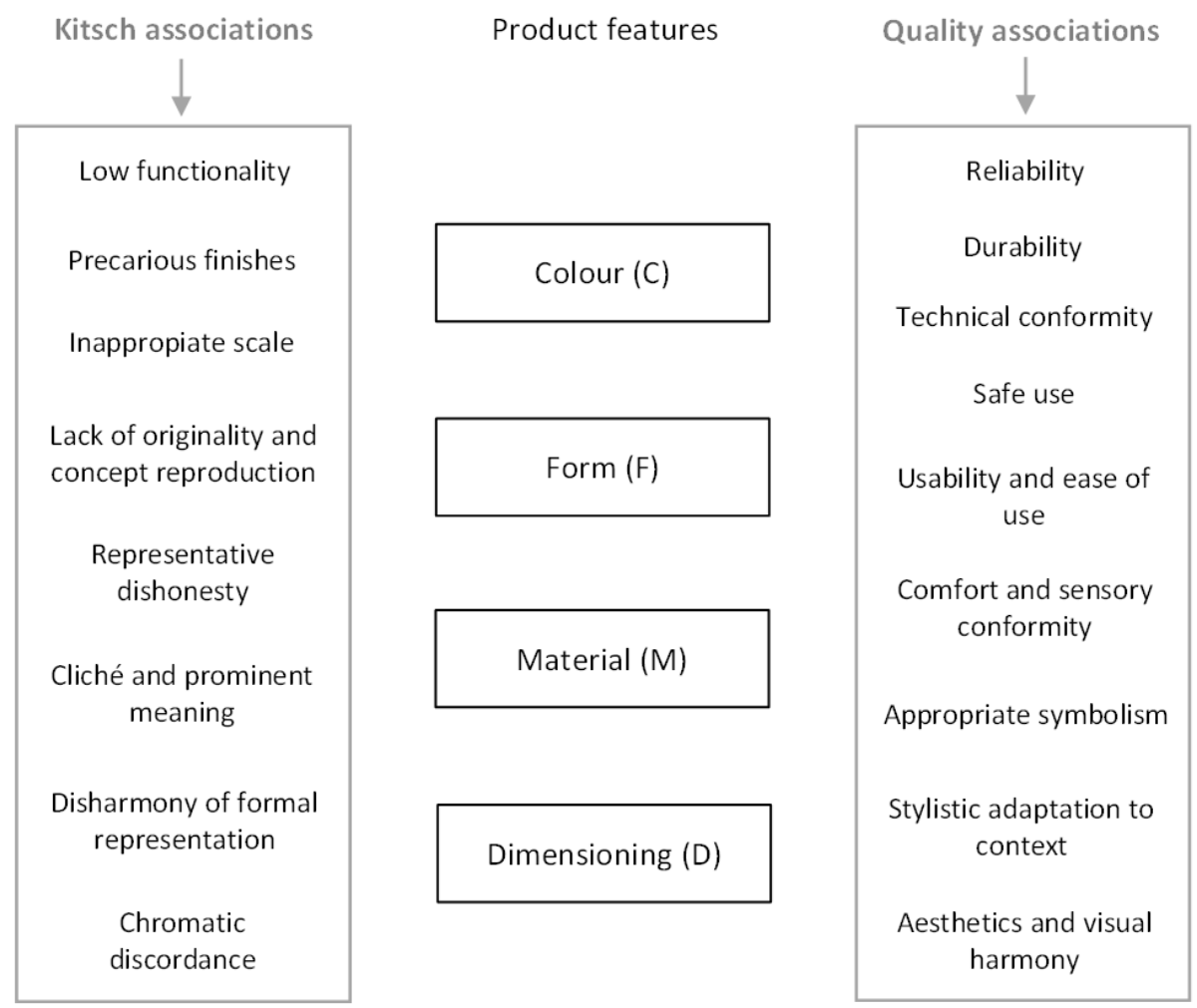

Figure 2. Associations of kitsch and quality from the perspective of product features

Considering the product typology and its destination of use, it is proposed as a first phase of the analysis the determination of the features importance rank, taking into account the degree to which they impact the described concepts associated to the products perceived value. Thus, considering the eigenvector model [21], the product features (colour, form, material and dimensioning) will be analysed comparatively, their relative importance being noted according to Saaty [22] with values from 1 (equal importance) to 9 (absolute importance), as represented in the relations from (1) to (4).

$$
\begin{gathered}
P=\left\{p_{1}, p_{2}, \ldots, p_{n}\right\} \leftrightarrow P=\{\mathrm{C}, \mathrm{F}, \mathrm{M}, \mathrm{D}\} \\
\sum_{i=1}^{n} p_{i}=1 \\
A=\left(\begin{array}{cccc}
p_{1} / p_{1} & p_{1} / p_{2} & \cdots & p_{1} / p_{n} \\
p_{2} / p_{1} & p_{2} / p_{2} & \cdots & p_{2} / p_{n} \\
\cdots & \cdots & \cdots & \cdots \\
p_{n} / p_{1} & p_{n} / p_{2} & \cdots & p_{n} / p_{n}
\end{array}\right)=\left(\begin{array}{cccc}
\mathrm{C} / \mathrm{C} & \mathrm{C} / \mathrm{F} & \mathrm{C} / \mathrm{M} & \mathrm{C} / \mathrm{D} \\
\mathrm{F} / \mathrm{C} & \mathrm{F} / \mathrm{F} & \mathrm{F} / \mathrm{M} & \mathrm{F} / \mathrm{D} \\
\mathrm{M} / \mathrm{C} & \mathrm{M} / \mathrm{F} & \mathrm{M} / \mathrm{M} & \mathrm{M} / \mathrm{D} \\
\mathrm{D} / \mathrm{C} & \mathrm{D} / \mathrm{F} & \mathrm{D} / \mathrm{M} & \mathrm{D} / \mathrm{D}
\end{array}\right) \\
a_{i j}=1 / a_{j i}, a_{i j}=a_{i k} / a_{j k}, i, j, k=1, \ldots, n .
\end{gathered}
$$

where, $P$ represents the importance vector of the coefficients, $A$ is the matrix of relative importance of the criteria, $a_{i j}$ represents the position of a term, $\mathrm{C}$ is representative for colour, $\mathrm{F}$ is representative for form, $\mathrm{M}$ is representative for material and $\mathrm{D}$ is representative for dimensioning. 
Considering the obtained $A$ matrix, based on the characteristic equation represented in relation (5), the value for $\lambda_{\max }$ will be obtained. By replacing in relation (6) the value for $\lambda_{\max }$, the relation will take the form presented in relation (7), based on which will be determined the corresponding values of importance $p_{i}$ of the four proposed features.

$$
\begin{aligned}
& \operatorname{det}(A-\lambda I)=0 \\
& A P^{T}=\lambda_{\max } P^{T} \\
& \left(\begin{array}{cccc}
1-\lambda_{\max } & \mathrm{C} / \mathrm{F} & \mathrm{C} / \mathrm{M} & \mathrm{C} / \mathrm{D} \\
\mathrm{F} / \mathrm{C} & 1-\lambda_{\max } & \mathrm{F} / \mathrm{M} & \mathrm{F} / \mathrm{D} \\
\mathrm{M} / \mathrm{C} & \mathrm{M} / \mathrm{F} & 1-\lambda_{\max } & \mathrm{M} / \mathrm{D} \\
\mathrm{D} / \mathrm{C} & \mathrm{D} / \mathrm{F} & \mathrm{D} / \mathrm{M} & 1-\lambda_{\max }
\end{array}\right) *\left(\begin{array}{l}
p_{1} \\
p_{2} \\
p_{3} \\
p_{4}
\end{array}\right)=0
\end{aligned}
$$

where, $I$ is the identity matrix, $\lambda_{\max }$ represents the highest eigenvalue and $P^{T}$ is the ratios corresponding column vector.

The values thus obtained for the importance coefficients of the features contribute to the subsequent determination of the values of importance of the associated attributes that are to be presented.

\section{Generated concepts and associated attributes}

Considering the four features, it will be analysed the influence relationship between them in relation to the described associations, thus being generated 16 relationships described along with the associated attributes, presented as follows:

- Colour / Colour (CC) - It will be analysed the degree of harmony generated by the chromatic scheme [23] considering the impact on the aesthetics of the product;

- Colour $\rightarrow$ Form (CF) - Taking into account the chromatic scheme in relation to the form, it will be analysed the extent to which the visual representation of the product reflects its function [24];

- Colour $\rightarrow$ Material (CM) - The extent to which the chromatic elements are symbolically adapted to the user's category will be analysed taking into account both the significance of the materials [25] presented in the natural form and those covered by colour and the meaning thus associated;

- Colour $\rightarrow$ Dimensioning (CD) - Considering the product's colour scheme, it will be analysed the extent to which the amount of colour associated with the product surfaces generates harmony [26];

- Form $\rightarrow$ Colour (FC) - It will be established the extent to which the forms that define the product in relation to the associated chromatic scheme generate the presence of the cliché [27] and prominent meaning;

- Form / Form (FF) - It will be analysed the degree of reproduction (considering other concepts already known) of both the general form of the product and the forms identified in the decorative elements;

- Form $\rightarrow$ Material (FM) - Taking into account the type of material and its implications, it will be established the extent to which the form is adapted to the purpose of use of the product;

- Form $\rightarrow$ Dimensioning (FD) - Taking into account the form in relation to the dimensioning elements of the product, it will be analysed the extent to which the product is stylistically adapted to the context of use;

- Material $\rightarrow$ Colour (MC) - The degree of representative honesty of the product materials [28] will be analysed, taking into account the presence of chromatic reproduction of other materials;

- Material $\rightarrow$ Form (MF) - It will be established the way in which the material in its relation with the formal elements presents a corresponding degree of finishing;

- Material / Material (MM) - The extent to which the material impacts the reliability and durability of the product will be established [29]; 
- Material $\rightarrow$ Dimensioning (MD) - Taking into account the dimensioning elements, it will be established to what extent the product through its materials ensures comfort in use and reflects the appropriate compressibility and roughness [30];

- Dimensioning $\rightarrow$ Colour (DC) - Considering the chromatic reproduction of already existing concepts, it will be considered to what extent the scale is replicated, taking into account that a high degree of detail reproduction of other concepts directly affects the honest representation of the products' destination;

- Dimensioning $\rightarrow$ Form (DF) - Considering the dimensioning of the product, it will be analysed the extent to which its form adapts to the context, since for a considered product form, the dimensioning of certain components as well as of the product as a whole can have different meanings in relation to the expected context of use;

- Dimensioning $\rightarrow$ Material (DM) - It will be analysed the extent to which the dimensioning of the product in its relationship with the product's materials is in accordance with technical standards and ensures safe use;

- Dimensioning / Dimensioning (DD) - It will be considered the extent to which the dimensioning of the product reflects an appropriate scale (without being defined by unnecessary oversizing or even undersizing) both in regards to usability as well as symbolically.

As it was described, the relations thus formed are represented by the direct impact of a feature (CC, FF, MM and DD), along with the way in which a certain feature in correspondence with the influence of another one considered (CF, CM, etc.) influence the associated concepts of the perceived value of the product.

\section{Notation and results interpretation}

The assessment of the product starts from completing the format proposed in Figure 3 considering the relational concepts of the features and their associated antagonistic attributes. In the numerical marking, for each of the 16 relationships, it will be taken into account the extent to which the product relates to its corresponding setting from -5 to +5 , where zero represents the neutrality of the concept associated with the attribute.

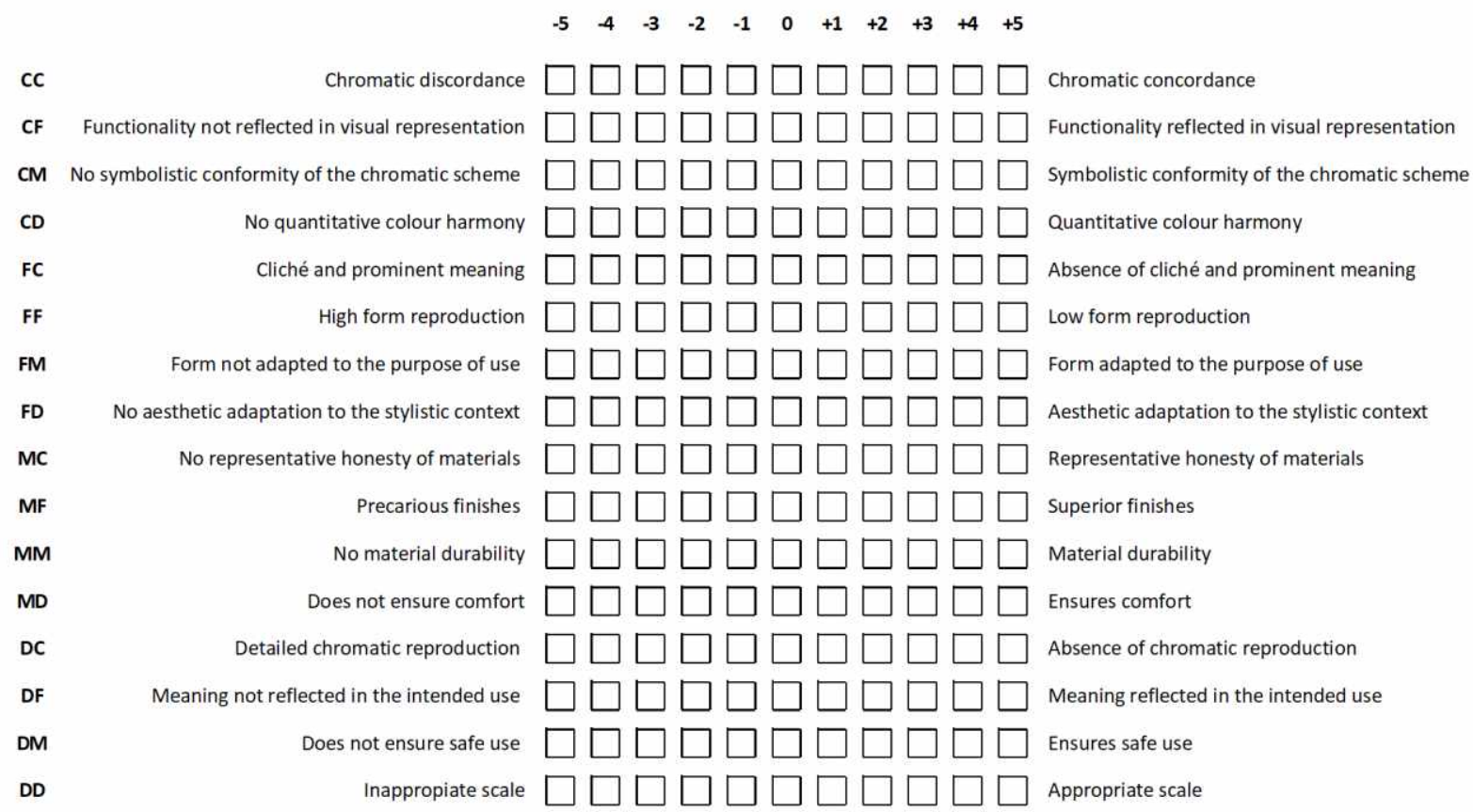

Figure 3. Assessment format for attribute notation of assigned values 
Following the notation, the values obtained within the format are representative for the matrix of assigned values $V$, the position of the pairs within the matrix being represented in relation (8) as the generated connections between the four features.

Regarding the corresponding importance values, based on the values previously obtained for the basic ratios of the features $p_{i}$ presented in relation (9) (values that were deduced from relation 7), in order to determine the ratios of the attributes, the $p$ values will be correlated in pairs as seen in relation (10). Thus, considering the $r_{i j}$ ratios of the attributes, in relation (11) it was presented the newly generated square matrix $R$ of order 4, for which the main diagonal (defined by $i=j$ ) is representative for the attributes ratios generated unilaterally by the product features.

$$
\begin{gathered}
V=\left(\begin{array}{cccc}
\mathrm{CC} & \mathrm{CF} & \mathrm{CM} & \mathrm{CD} \\
\mathrm{FC} & \mathrm{FF} & \mathrm{FM} & \mathrm{FD} \\
\mathrm{MC} & \mathrm{MF} & \mathrm{MM} & \mathrm{MD} \\
\mathrm{DC} & \mathrm{DF} & \mathrm{DM} & \mathrm{DD}
\end{array}\right)=\left(\begin{array}{llll}
v_{11} & v_{12} & v_{13} & v_{14} \\
v_{21} & v_{22} & v_{23} & v_{24} \\
v_{31} & v_{32} & v_{33} & v_{34} \\
v_{41} & v_{42} & v_{43} & v_{44}
\end{array}\right) \\
P=\left\{p_{1}, p_{2}, \ldots, p_{n}\right\} \\
r_{i j}=p_{i} * p_{j} \\
R=\left(\begin{array}{llll}
r_{11} & r_{12} & r_{13} & r_{14} \\
r_{21} & r_{22} & r_{23} & r_{24} \\
r_{31} & r_{32} & r_{33} & r_{34} \\
r_{41} & r_{42} & r_{43} & r_{44}
\end{array}\right) \\
M=\sum_{i=1}^{n} r_{i j} v_{i j}
\end{gathered}
$$

where, $V$ is the matrix of assigned values, $P$ represents the vector of importance of the features, $R$ represents the matrix of attributes ratios, $M$ is the indicator for perceived value, $r$ represents the importance ratio of an attribute and $v$ represents the assigned value of an attribute.

The indicator associated to the perceived value of the product $M$ will be determined by the sum of the attributes in relation to their importance as presented in relation (12). The $M$ indicator can take values in the range $[-80,80]$, as -80 is representative for the lowest perceived value and +80 for the highest perceived value of the product. Following the assessment, the interpretation of the results should be performed in relation to the position of the obtained value within the established interval. Thus, the $M$ indicator was proposed as the final element of interpretation of the analysis, for which, the results can be influenced both by the assigned values in accordance with the degree of fulfilment, as well as the ratio setting, in which case a major relevance is represented by the relative assignment of importance in relation to the product typology and the way in which the product features are considered to be influenced by the associated concepts to the perceived value.

\section{Conclusions}

The application of the proposed model starts from establishing the relative importance of the features depending on the typology of the product in relation to the way in which they impact the described concepts associated to the products perceived value, following that after noting the assessment format, the values thus assigned will be correlated with those obtained from the matrix of importance, based on them being obtained the final value of the indicator of perceived value of the product in correspondence with the intervals established for the interpretation of the results.

Unlike extrinsic ones (as price or brand image), the intrinsic components of perceived value are less obvious and imply the proper understanding of the impact of product characteristics on its final design. Also, even if the real value of the product is realized, the wheel of production, demand and consumption could generate the situation in which there is no better alternative and it is obvious there is no guarantee that the reason we produce poor quality products is due to demand, as is the possibility 
that overpopulation with inferior goods may also be due to replication of existing products as an apparent security of commercial success, or even small mass production companies intended for the lower classes cannot afford or refuse to invest in development or are not even aware of the need to do so. This situation could limit the access to better products that could have been obtained at the same cost of production and in this case, even if the consumer could be aware of the product's real value, he will compromise as trying to choose the best option from those available, as one of the most harmful components of kitsch is the association with precarious products defined by poor quality [31] which has a direct impact on product reliability and on a large scale on sustainability [32].

The presented study does not claim to be an algorithm that would ensure total product quality nor would eliminate the existence of kitsch products as souvenirs that lack in functionality, however in the case of industrial products that are designed for a specific purpose of use, the model can be applied as a framework in assessing the perceived value of a product considering concepts associated with kitsch and quality in relation to product features and corresponding design elements. Moreover, if it is considered even from the beginning in the concept design assessment phase and not just on existing products, the proposed model can contribute to the improvement of the perceived value of the product even since the production stage, which could contribute finally to the perceived quality and also, regarding certain aspects even on the actual quality of the product.

\section{References}

[1] S. STEWART: Contemporary Kitsch: An examination through creative practice, Edith Cowan University, 2015. Thesis retrieved from http://ro.ecu.edu.au/theses/171

[2] S. TIMUR: Objects of Resistance and Expression: Rethinking the Concept of 'Kitsch' in the Everyday life of the Modern Individual Contemporary Kitsch: An examination through creative practice, $4^{\text {th }}$ Design and Emotion Conference, ODTÜ Ankara, 2004.

[3] G. DORFLES: Kitsch - An anthology of bad taste, Studio Vista Limited, London, 1970. SBN 289797608.

[4] C. E. EMMER: Kitsch Against Modernity, Art Criticism, 13 (1), 53-80, 1998. ISSN: 0195-4148

[5] P. WARD: Kitsch in Sync - A Consumer's Guide to Bad Taste, Plexus Publishing Limited, London, 1991.

[6] M. KJELLMAN-CHAPIN: Kitsch: History, Theory, Practice, Cambridge Scholars Publishing, UK, 2013.

[7] M. CĂLINESCU: Five Faces of Modernity: Modernism, Avant-garde, Decadence, Kitsch, Postmodernism, Duke University Press Durham, 1987. ISBN 0-8223-0726-X

[8] S. A. ORTLIEB, C. C. CARBON: A Functional Model of Kitsch and Art: Linking Aesthetic Appreciation to the Dynamics of Social Motivation, Frontiers in Psychology, 9 (2437), 2019. DOI 10.3389/fpsyg.2018.02437

[9] M. RYYNÄNEN: Contemporary Kitsch: The Death of Pseudo Art and the Birth of Everyday Cheesiness (A Postcolonial Inquiry), Terra Aestheticae, 1 (1), 70-86, 2018.

[10] A. ERGÜL: Walter Benjamin and Kitsch Politics in the Phantasmagorical Age, Carleton University, Ottawa, Ontario, 2016. Thesis retrieved from https://curve.carleton.ca

[11] C. NARTER, A. BAJMAKU: Bad Design to Kitsch: Eastern Point of View, UBT International Conference, 2017. DOI 10.33107/ubt-ic.2017.2

[12] S. L. T. MCGREGOR, K. GREENFIELD: Global Consumer Education: Its Time Has Come, The Journal of Consumer Education, 14, 1996.

[13] A. BONFANTI, F. BRUNETTI: Customer Education, Evaluation Skills And Perceived Value:

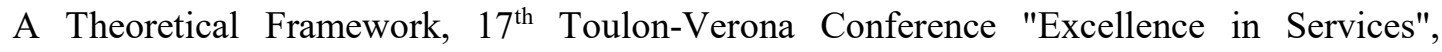
Liverpool John Moores University, Liverpool, UK, 2014.

[14] S. VANTAMAY: Understanding of Perceived Product Quality: Reviews and Recommendations, BU Academic Review, 6 (1), 2007.

[15] J. C. SWEENEY, G. N. SOUTAR: Consumer perceived value: The development of a multiple item scale, J. of Retailing, 77 (2), 203-220, 2001. DOI 10.1016/S0022-4359(01)00041-0 
[16] V. A. ZEITHAML: Consumer Perceptions of Price, Quality and Value: A Means-End Model and Synthesis of Evidence, Journal of Marketing, 52 (3), 2-22, 1988.

[17] G. J. SZYBILLO, J. JACOBY: Intrinsic Versus Extrinsic Cues as Determinants of Perceived Product Quality, Journal of Applied Psychology, 59 (1), 74-78, 1974. DOI 10.1037/h0035796

[18] A. D. GARVIN: What Does 'Product Quality' Really Mean, MIT Sloan Management Review, 26 (1), 1984.

[19] G. N. KENYON, K. C. SEN: Customer's Perceptions and the Dimensions of Quality, Western Decision Sciences Conference, 2011. DOI 10.13140/2.1.4738.4326

[20] A. E. CRĂCIUN: A review on quality from the perspective of industrial product design assessment, Technium Journal, 2 (7), 303-309, 2020. DOI 10.47577/technium.v2i7.2180

[21] M. ANDRAȘIU, A. BACIU, A. PASCU, E. PUȘCAȘ, A. TAȘNADI: Metode de Decizii Multicriteriale (Multi-Criteria Decision Methods), Editura Tehnică, Bucharest, 1986.

[22] T. L. SAATY: Decision making with the analytic hierarchy process, Int. J. Services Sciences, $1(1), 83-98,2008$.

[23] J. ITTEN: The Elements of Color, Van Nostrand Reinhold Company, 1970.

[24] L. M. GERHARD: The unity of form and function: Making sense of product design from a consumer's point of view, University of Texas at Austin, 2008. Thesis retrieved from https://repositories.lib.utexas.edu/handle/2152/3927

[25] C. B. DATTA: Emotive Materials: Towards a shared language of the meaning of materials, MIT, School of Architecture and Planning, 2016. Thesis retrieved from https://dspace.mit.edu/handle/1721.1/107574

[26] A. E. CRĂCIUN: A Study On Product Color Ratio Based On Aesthetic Principles In Industrial Design Assessment, $35^{\text {th }}$ IBIMA Conference, 2020.

[27] S. BINKLEY: Kitsch as a Repetitive System: A Problem for the Theory of Taste Hierarchy, Journal of Material Culture, 5 (2), 131-152, 2020. DOI 10.1177/135918350000500201

[28] I. HOLM: Ideas and beliefs in architecture and industrial design: How attitudes, orientations, and underlying assumptions shape the built environment, Oslo School of Architecture and Design, 2006. Thesis retrieved from http://citeseerx.ist.psu.edu/viewdoc/download?doi=10.1.1.115.6286\&rep=rep1\&type=pdf

[29] S. N. B. HODGSON, J. F. HARPER: Effective use of materials in the design process - more than a selection problem, The $7^{\text {th }}$ International Engineering And Product Design Education Conference, Delft University of Technology, 2004.

[30] W. M. BERGMANN TIEST, A. M. L. KAPPERS: Analysis of haptic perception of materials by multidimensional scaling and physical measurements of roughness and compressibility, Acta Psychologica, 121 (1), 1-20, 2006. DOI 10.1016/j.actpsy.2005.04.005

[31] Merriam Webster Dictionary: Definition of kitsch - Retrieved from https://www.merriamwebster.com/dictionary/kitsch

[32] J. HAN, P. JIANG, P. R. N. CHILDS: Metrics for Measuring Sustainable Product Design Concepts, Energies, 14 (12), 3469, 2021. DOI 10.3390/en14123469 